\title{
基于再野化理论的东北虎豹国家公园发展前瞻 兼评荒野保护思想与实践
}

\author{
王宏新 ${ }^{1,2}$, 邵俊霖 1,3 , 于姝婷 ${ }^{3}$, 王迎辉 ${ }^{3}$, 冯 钰 $^{3}$ \\ (1. 北京师范大学全球共同发展研究院, 北京 $100875 ; 2$. 北京师范大学中国社会管理研究院/社会学院, \\ 北京 $100875 ; 3$. 北京师范大学政府管理学院, 北京 100875)
}

\begin{abstract}
摘要：建立以国家公园为主体的自然保护地体系, 是推进“五位一体”总体布局的重大理论与 实践创新。通过对荒野保护思想源起、发展历程和实践的梳理, 阐述了荒野与自然保护地体系 之间的内在关系。在此基础上,着重介绍了再野化理论中的“3C”模型、营养级再野化和“TSD” 模型, 并运用 NVivo 对《东北虎豹国家公园总体规划(2017-2025 年)(征求意见稿)》进行政策 文本分析。《规划》较好地体现了荒野保护思想, 符合再野化理念, 营养级再野化特征较为显著, 但人工干预色彩浓厚,生态再野化特征突出。关注荒野与再野化是城市化、工业化发展到相对 成熟阶段的必然要求,国家公园应持续进行再野化实践,为荒野科学与工程发展提供支撑。
\end{abstract}

关键词：荒野;再野化;自然保护地体系;国家公园

《关于建立以国家公园为主体的自然保护地体系的指导意见》明确了自然保护地在生 态建设中的核心地位与作用，同时指出要科学划定自然保护地类型。世界自然保护联盟 （IUCN）《自然保护地管理分类应用指南》将自然保护地分为六大类，其中，荒野保护地 因其首要目标即为保护自然区域的长期生态完整性，正受到越来越多的重视 ${ }^{[1]}$ 。本文通过 梳理荒野保护思想源起与发展历程, 着重阐述荒野与自然保护地体系之间的内在关系, 并在对国际再野化理论前沿进行述评的基础上，运用 NVivo 对《东北虎豹国家公园总体 规划（2017-2025年）(征求意见稿）》（以下简称《规划》）进行文本分析，对东北虎 豹国家公园发展进行前瞻性探讨并对我国荒野保护、再野化工程以及建立荒野科学与工 程学科等问题进行研究。

\section{1 荒野保护思想:源起与发展}

\section{1 国外“荒野”(Wilderness) 词义及荒野观嬗变}

“荒野” (wilderness)，其词根为 wild，在现今日耳曼语系和古代英语中均拼写为 “wilde”, 作为一个形容词来指未被驯服或驯化的植物和动物, 后来逐渐演化为野生动物 所处的地方, 今天则用来表示以野生动物占据为本质特征的地方。正因如此, 荒野被理 解为 “不受驯养者或耕种者意志支配的、恣意的土地” (to be self-willed land, not subjected to the will of a domesticator or cultivator ${ }^{[2]}$ 。众多西方国家中, 美国的历史、文化发 展与荒野联系最为密切。19世纪末 20 世纪初，伴随着西进运动，美国荒野艺术、文学、

收稿日期：2020-02-07; 修订日期：2020-10-19

基金项目：国家社会科学基金项目（19AGL024）

作者简介：王宏新（1976- ), 男, 山西长治人, 博士, 教授, 博士生导师, 研究方向为经济一社会一生态耦合、可 持续发展与治理。E-mail: bnuwhx@126.com 
科学和政策方面达到了一个高峰。梭罗留下名言 “世界存乎于荒野” (In Wildness is the Preservation of the World ${ }^{[3]}$, 约翰 - 谬尔（John Muir）推动约塞米蒂山谷纳人国家公 园。同期，英国通过了《汉普斯特德荒野法案》（Hampstead Heath Act，1871），规定市 政当局有权对荒野进行排水、平整和改善（如种植树木或灌木），但改善活动必须秉持尽 可能维持荒野 “自然面貌” (natural aspect) 的原则, 成为近代英国环境保护史上的经典 案例 ${ }^{[4]}$ 。进人 20 世纪, 荒野可以带给人生理、精神和审美三重作用的观点被广泛接受 ${ }^{[5]}$ 。 奥尔多 - 利奥波德 (Aldo Leopold) 推动了国家森林内土地作为无路荒野 (roadless wilderness）的单独分类 ${ }^{[6]}$ ，他对生物共同体（biotic community）的尊重以及将荒野作为联 邦土地重要用途的愿景, 对《荒野法案》（The Wilderness Act）出台产生了深刻影响, 因 而被广泛认为是 “荒野法先驱”。

\section{2 中国传统荒野观与荒野开发保护实践}

中国从古至今的荒野开发与保护是全球荒野保护实践的重要组分。现代意义上的荒 野本身是一个外来词, 加之古文多用单音节词等原因, 荒野一词在中国传统典籍中出现 较少。但是, 中华文明中, 开发荒野、保护荒野的思想和实践自古有之。《山海经・大荒 西经》《尚书・商书・说命下》《贞观政要》等作品都描述过荒野, 但多是基于丰富的想 象或朴素的个人经验, 认为荒野是危险、怪诞的。然而为了生存和发展, 先民对荒野的 开发、利用与保护又是具体而久远的。太公（吕尚）封于营丘，“辟草莱而居焉”; 楚国 祖先 “䇤路蓝缕, 以启山林”, 郑桓公与商人 “庸次比耦, 以艾杀此地, 斩之蓬蒿藜蒦而 共处之” [7]。如此种种，都是对荒野进行开发利用的典型例子。进人春秋战国时期，随着 铁器广泛使用, 开垦荒地的能力不断增强。随着大量垦荒带来的负面影响, 先民们逐渐 认识到保护生态环境的重要性, 于是开展休耕, 限制渔猎。正是由于开发与保护相结 合，推崇 “天人合一” 思想的中华文明才能在有限的土地上不断发展壮大，历经种种挑 战而依旧朝气蓬勃。

\section{3 现代国家荒野保护体系的产生与发展}

一般意义上，荒野涉及自然荒野与荒野观念两个维度，自然荒野是荒野观念的物质 基础，荒野观念则是荒野保护的思想支撑 ${ }^{[8]}$ 。现代荒野保护实践肇始于 20 世纪 50-60 年 代，美国二战后迎来基础设施建设大潮，自然资源和生态环境挑战空前。时任荒野协会 主席霍华德 - 扎尼泽（Howard Zahniser）认识到，唯有立法才能彻底根除荒野所面临的 威胁 ${ }^{[9]}$, 于是着手起草《荒野法案》, 经过长达 8 年的博峦和不断修改, 最终于 1964 年签 署通过。

《荒野法案》最突出的贡献在于明确了荒野的法律定义，即 “荒野与人类及其人造景 观占据的区域不同，它是对一个特定区域的（法律）确认，在这个区域里，土地及其生 物群落尚未受到人类控制 (untrammeled)，人类仅仅是短暂的访客”。法律进一步明确了 “荒野区”（area of wilderness）的概念，即 “荒野区是指依旧保存着原始特征和影响、尚 未被永久改良（permanent improvements）或人类居住的、未开发的联邦土地。”法律界 定了荒野区的四个本质特征：（1）通常主要受自然力量所影响，人工痕迹不明显; （2）具有可供隐居（solitude）或一种原始、自由自在地娱乐消遣的良好机会;（3）在土 地范围上至少要有 5000 英亩 (约 $20 \mathrm{~km}^{2}$ ) 或足够大到能实现荒野保护和在未损害条件下 利用; (4) 这一区域可能还具有地质、生态或其他科学特征, 且具有教育、景观或历史 
价值” ${ }^{[10]}$ 。《荒野法案》代表了美国国家荒野保护体系（National Wilderness Preservation System, NWPS）的正式确立，成为联邦土地管理体系的重要组成部分。经过半个多世 纪的发展，美国国家荒野保护面积逐年扩大，荒野区得到了永久性和系统性的保护 ${ }^{[11]}$ 。 除美国外，欧洲也高度重视荒野保护，先后出台了一系列保护措施和方案。

\section{4 自然保护地体系与荒野地保护区}

自然保护地对于生态多样性保护至关重要，是理解人类与自然界相互作用、理解整 个地球生态系统的基础之一。世界各国对自然保护地的理解尚存在不同，有些国家认为 自然保护地是一个通用名词，包括各种陆地和水域管理类型；有些国家则认为自然保护 地是某一专门用于自然资源保护的特定形式的管理体系。IUCN 对自然保护地下了一个更 加具体、可被广泛接受的定义，即 “为实现对自然及其生态系统服务和文化价值的长期 保护，通过法律或其他有效方式获得承认、得到承诺和进行管理的明确界定的地理空 间” [12]。在此基础上，IUCN 于 1994 年首次将 “荒野保护地” 明确界定为一种自然保护 地类型（IUCN-Ib），并在 2008 年将其定义为无永久性或者明显人类居住痕迹的、大部分 保留原貌（或仅有细微变动）、保存着自然特征和影响的区域 ${ }^{[1]}$ 。区别于严格的自然保护 地，荒野保护地对人类活动的限制程度稍轻一些，与国家公园在面积以及保护生态系统 功能的目标上比较接近。

2016年，《IUCN 荒野保护地管理指南》发布，美国、加拿大、澳大利亚、日本等在 内的全球 48 个国家已通过法律正式确认了 IUCN-Ib 类保护地 ${ }^{[13]}$ 。目前，中国已建立包括 国家公园、自然保护区、世界遗产、风景名胜区等在内的保护地体系，但尚未将“荒 野” 纳人土地利用分类，而是在生态治理中推行 “宜荒则荒” 原则。该原则有助于发挥 荒野地防风固沙、保育土壤、涵养水源、保育生物多样性等多种生态功能，也可促进农 业结构合理调整 ${ }^{[14,15]}$ 。但国内对荒野在生态系统中的重要性认识尚不充分，尤其是近年来 又进人到新一轮高强度 “四荒地” 开发利用阶段，低效的农业开发对生态环境产生的破 坏得不偿失，湖北省当阳市湖心岛就是典型案例 ${ }^{[16]}$ 。坚持 “宜荒则荒” 原则，发挥荒野 的完整生态系统作用，尤其在保护物种和生物群落作用等方面，任务已非常紧迫。

\section{2 再野化理论: 荒野科学与工程的新发展}

1998 年, 《Wild Earth》期刊上发表了 Soule 等 ${ }^{[17]}$ 的《再野化和生物多样性：大陆保护 的补充性目标》, 开启了再野化 (rewilding) 理论先河。该文尖锐地指出, 直到 20 世纪 80 年代中期, 保护荒野只是出于美学追求和伦理审视。伴随着荒野保护行动发展起来的 再野化理论，扩展了荒野保护的内涵，极大地促进了荒野科学的发展。

\section{1 再野化理论的提出}

Soule 等 ${ }^{[17]}$ 提出的再野化理论, 是基于 20 世纪 80 年代以来保护生物学领域的研究, 尤其是在保护和恢复生物多样性、食物网、栖息地以及关键物种在调节陆地生态系统中 的作用等交叉科学领域的研究，他们将基于大型食肉动物调节作用、恢复大片荒野的 “再野化思想” (the idea of rewilding) 称为 “现代保护运动的第四件大事”。Soule 等 ${ }^{[17]}$ 明 确提出了再野化的三个重要特征，即“核心区”（Cores）、“廊道” (Corridors) 和“食肉 动物” (Carnivores)，也简称为 “ $3 \mathrm{C}$ ”模型。“3C” 模型的核心是，建立荒野地之间的连 通性, 通过保护或再引人, 让顶级食肉动物和其他关键物种回归荒野, 从而恢复更大范 
围的景观 ${ }^{[18]}$ 。该模型兼具手段与目的属性，“目的” 是保护荒野，“手段” 则指发挥关键 物种在维持生态结构、多样性和整个生物结构复原方面所起的重要作用。“3C”模型在 北美得到广泛应用，有效保护了生态系统完整性，如黄石公园通过狼群引人，有效控制 了鹿群数量, 恢复了生态平衡。但是, Soulé等 ${ }^{[17]}$ 也认为, 将再野化或任何其他保护工具 看作是保护和治愈土地创伤的唯一手段都是无益的。拯救生物界属于复杂性工程, 需要 多种方法相互补充。

\section{2 “营养级再野化”}

历经二十余年发展，除“3C”模型外，再野化已演进出多种定义，如更新世巨型动 物引人、岛屿上的物种引人、通过物种引人实现景观恢复、生产性土地废弃、驯养野生 动物放归等 ${ }^{[19]}$ 。在实践方面, 作为世界荒野运动中的创新者, 欧洲荒野保护也非常深 人, 具有过程式引导、终端式培育、渐进式延展等特色, 为世界范围内荒野景观保护提 供了有益借鉴 ${ }^{[20]}$ 。再野化理论研究与实践探索取得的一个重要共识就是强调将其作为一 种修复方法和工程, 通过系统的相互促进和支持, 最大化地减少人类干预的交互生态过 程, 以恢复和维持复杂的生态系统。但是, 近来研究表明, 某种程度的管理对于替代因 人类活动而消失的生态系统过程或维持文化景观至关重要，例如引人替代性的关键物 种。在此过程中, 产生了一个重要概念——“营养级再野化” (trophic rewilding), 即引 人非本地、大型食肉动物和大型食草动物等重点物种, 以作为对数百年或千年前灭绝物 种的生态替代, 从而恢复生物多样性和生态系统。Svenning 等 ${ }^{[21}$ 强调需要实施应用性的 计划, 包括假设检验和科学监测, 特别是评估营养复杂性作用以及景观设置、土地使用 和气候变化之间的相互影响, 并开发全球范围内再野化效益优化和减少人类一野生动植 物冲突的工具。然而, 营养级再野化研究中人工干预的强度仍然备受争议 ${ }^{[22]}$, 对野生动 物的实证研究仍然不够成熟, 目前为止仍处于观点介绍阶段。

\section{3 基于社会生态系统与复杂性理论的“TSD”模型}

Perino 等 ${ }^{[23]}$ 基于社会生态系统弹性与复杂性 理论提出了一个理论框架, 将营养级复杂性 (trophic complexity)、随机扰动 (stochastic disturbances) 和扩散 (dispersal) 作为自然生态系 统动力学的三个重要组成部分, 认为这一动态 进程的恢复及其相互作用, 可提高生态系统自 我可持续性, 应成为再野化的核心, 这一理论 也称为 “TSD” 模型。

“TSD” 模型实则上是一种生态再野化 (ecological rewilding), 即强调对废弃景观生态退化 的被动管理, 因而也称为 “被动再野化” ( passive rewilding)。生态再野化行为主要包括建立 禁猎区、低干预林业管理、剥离农业用地、移 除扩散障碍物和恢复自然洪水区 ${ }^{[23]}$ 。“TSD” 模 型的直接目的是恢复生态功能, 而非恢复特定生 物多样性; 同时, 该理论认为再野化的影响是动

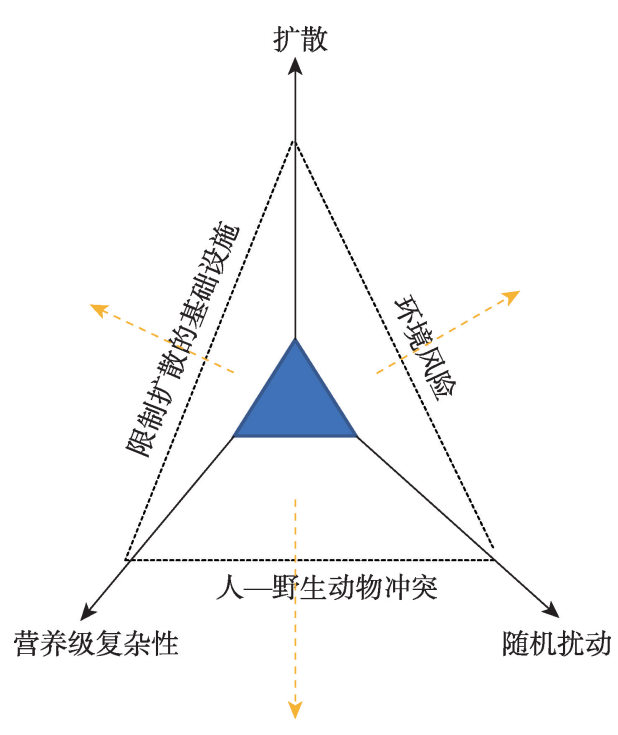

注: 模型来源于 Perino 等 ${ }^{[23]}$ 。

图 1 “TSD” 模型

Fig. 1 "TSD" Model 
态且不确定的。因此, 合理的再野化计划需要深刻理解相互作用的生态系统过程, 还需 要具备实施再野化项目的社会经济背景 ${ }^{[23]}$ 。

不幸的是，在Perino 等 ${ }^{[23]}$ 看来，目前的景观管理和保护政策并没有为再野化提供更 广泛实施的机会，例如欧盟共同农业政策激励了人们在低生产区进行农业活动，从而阻 碍了再野化机会; 一些恢复政策也仅仅是偏重于保护某些物种和栖息地。尽管如此, Perino 等 ${ }^{[23]}$ 还是对再野化充满信心，相信再野化能为生态系统恢复提供一种可能途径，并 成为生态恢复的主要方法, 得到全球生物多样性政策的关注。

此外, 再野化理论与土地政策密切相关。再野化理论提出之初, 经常面临来自公众 和学界的压力, 很少被认为是一项土地政策 ${ }^{[2]}$ 。近几年来，再野化成为自然保护领域热 门话题，欧美再野化土地政策得以推进 ${ }^{[25]}$ 。例如在英国，再野化已经被作为一种土地管 理纳人政策讨论和土地管理实践，并且探索出包括栖息地修复、自然放牧、引人特定物 种等主动再野化方法以及调整部分土地的消极再野化方法 ${ }^{[26]}$ 。随着各类生态危机、社会 危机凸显, 过度开发利用荒野、片面追求荒野经济价值的现象必须遏止, 生态的荒野土 地资源观亟需重塑 ${ }^{[2]}$ 。

总之, 过去 20 年来, 再野化理论受到学界重视并取得不少成绩。虽然在营养级再野 化方面尚未取得重大突破，但生态再野化研究方兴未艾，会为下一步营养级再野化的科 学与工程打下坚实基础; 反过来, 营养级再野化从理论构建到工程实验也将一步步变为 现实。

\section{3 《东北虎豹国家公园总体规划(征求意见稿)》文本分析}

为促进东北虎豹等珍稀物种保护，推动人与自然和谐共生，中国在东北虎豹主要栖 息地开展国家公园体制和国有自然资源资产体制两项试点。2018年3月，国家林业局会同 吉林、黑龙江两省发布了《规划》, 明确了东北虎豹国家公园（以下简称 “虎豹公园” ) 保护地类型划分, 并公开征求意见。12大保护地面积达 $557658 \mathrm{hm}^{2}$, 除涉及东北虎、豹 之外, 森林生态系统、生物多样性等也囊括在内, 优化了保护地体系, 出现了荒野保护 地维形 (表 1)。同时, 东北虎豹公园森林覆盖率、动物密度等规划目标明确, 自然资源 保护、东北虎豹保护也占监督管理指标较大比例（表2)，完全适用于再野化理论。中国 保护地建设一直面临保护与发展双重压力 ${ }^{[28]}$, 经历长期多头管理后, 中国国家公园体制建 设逐渐完善, 生态系统完整性保护理念得到广泛认可 ${ }^{[22]}$, 再野化则为生态保护修复提供了 新思路 ${ }^{[30]}$ 。基于此, 本文采用 NVivo 11.0 对《规划》文本进行解析, NVivo 具有强大的资 料编码、检索和分析功能，近年来被广泛应用于政策文本等非结构化数据 ${ }^{\left[{ }^{31]}\right.}$, 有助于厘清 关键变量, 深人探究《规划》蕴含的荒野保护思想和再野化理论元素。

\section{1《规划》较好地体现了荒野保护思想}

通过对《规划》内容进行 “词频” 分析, 可得到词语云 (图 2)。可见《规划》中词 语频率较高的有 “自然资源” “保护区” “栖息地” “东北虎” “管理局”等。

对《规划》文本进行按句编码，结果显示 “生态” “自然” “资源” “虎豹” 等编码点 编码数量均较多, 和 “词频” 分析有一定相关性。可见, 《规划》虽未直接提出荒野和再 野化，但其中体现出的对 “自然资源” “生态” 和 “自然” 的重视程度，非常符合荒野保 护思想尊重 “自然力量” 的典型特征。 
表 1 虎豹公园内保护地类型概况

Table 1 Summary of protected areas in Tiger and Leopard Park

\begin{tabular}{|c|c|c|c|c|}
\hline 序号 & 名称 & 保护对象 & 面积 $/ \mathrm{hm}^{2}$ & 保护管理站点个数/个 \\
\hline 1 & 珲春东北虎国家级自然保护区 & 东北虎、豹及其栖息地 & 108927 & 13 \\
\hline 2 & 汪清国家级自然保护区 & 东北红豆杉及针阔混交林生态系统 & 67434 & 6 \\
\hline 3 & 老爷岭东北虎国家级自然保护区 & $\begin{array}{l}\text { 东北虎、东北豹、猎物种群及温带 } \\
\text { 山地森林生态系统及其植被和生物 } \\
\text { 多样性 }\end{array}$ & 71218 & 3 \\
\hline 4 & 穆棱东北红豆杉国家级自然保护区 & 东北红豆杉及其森林生态系统 & 35648 & 12 \\
\hline 5 & 天桥岭省级自然保护区 & 珍稀野生动物 & 50055 & 5 \\
\hline 6 & 珲春松茸省级自然保护区 & 松茸及其森林生态系统 & 131721 & - \\
\hline 7 & 上屯湿地省级自然保护区 & $\begin{array}{l}\text { 沼泽湿地生态系统、濒危野生动植 } \\
\text { 物及东北虎、豹栖息地 }\end{array}$ & 6594 & 1 \\
\hline 8 & 兰家大峡谷国家森林公园 & 森林生态系统 & 10972 & - \\
\hline 9 & 六峰山国家森林公园 & 森林生态系统 & 34640 & - \\
\hline 10 & 图们江国家森林公园 & 森林生态系统 & 32678 & - \\
\hline 11 & 嘎呀河国家湿地公园 & 湿地生态系统 & 1161 & - \\
\hline 12 & $\begin{array}{l}\text { 密江河大麻哈鱼国家级水产种质 } \\
\text { 资源保护区 }\end{array}$ & $\begin{array}{l}\text { 大麻哈鱼等洄游性鱼类、细鳞鮏等 } \\
\text { 冷水性鱼类 }\end{array}$ & 6610 & - \\
\hline
\end{tabular}

注：根据《规划》内容整理，下同。

同时, 自动编码结果显示, 除 “生态” “自然” “保护”等编码点 外, “服务” “林场” “活动” “系统” “体验” “社区” 等编码数量也不容忽 视 (图3), 而这些编码点恰恰与再野 化理论密切相关。这反映出, 虎豹公 园成立后，对公园的保护将更加持久 和系统化, 公园生态多样性和生态系 统服务功能也会逐渐体现。

\section{2 符合再野化理念,营养级再野化特征显著}

为进一步探究《规划》与再野化理论的紧密程度, 在 “词频” 分析和 “自动编码” 的基础上, 结合 “荒野 一再野化” 理论框架和图 2、图 3 分析结果, 提取出自 然力量、核心区等 7 个关键词对《规划》进行文本搜 索。结果显示：“自然力量” 和 “大型食肉动物” 占比 最高, 分别为 $27.68 \%$ 和 $27.41 \%$; 其次为 “人为修复” 和 “原始体验”，分别为 $16.25 \%$ 和 $8.30 \%$ ；再次为 “廊 道” 和 “其他价值”, 分别为 $8.93 \%$ 和 $6.49 \%$; 最后为 “核心区”, 占比为 $4.95 \%$ (图 4)。

东北虎、东北豹等处于食物链顶端的旗舰种，在 20 世纪 90 年代末期几乎匿迹, 《规划》拟帮助和引导东

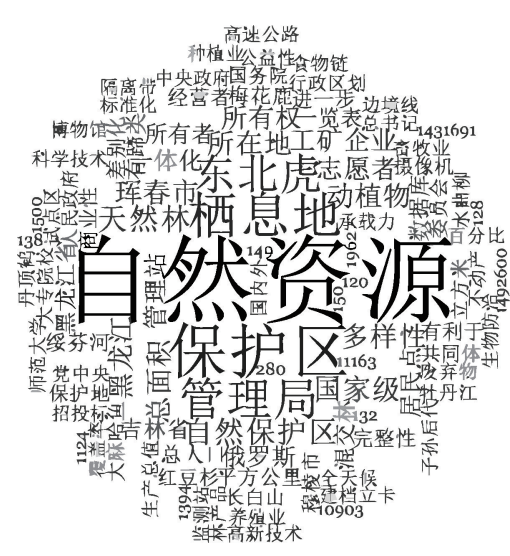

图 2 《规划》词语云

Fig. 2 Words clouds of the Plan 


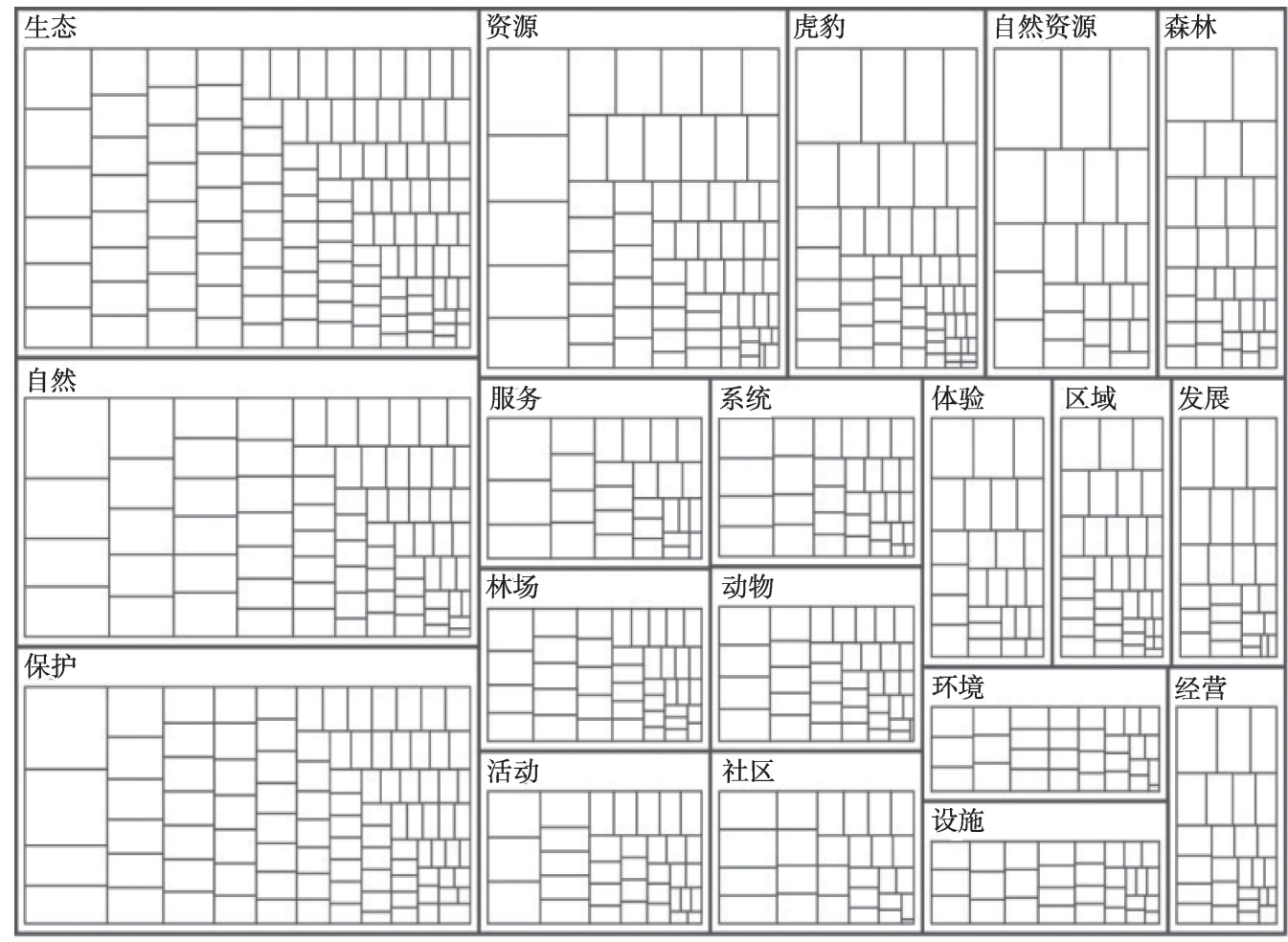

图 3 《规划》自动编码结果（面积代表数量）

Fig. 3 Auto-coding results of the Plan (area represents quantity)

北虎豹等大型动物回归栖息地，虽非引人外来大型食肉 动物, 也属于典型的营养级再野化范畴。从自动编码结 果中可以看出，《规划》中 “自然力量” 和 “大型食肉 动物” 占比最高, 体现出对自然及食物链的重视, 恰恰 也是 “ $3 \mathrm{C}$ ” 理论中食肉动物特征的体现，是再野化理论 中非常重要的一环。“词频” 分析和 “自动编码” 分析 结果显示, 除 “虎豹” 外, “动物” “动植物” “多样 性” “食物链” 等词在《规划》中所占比例也较大，亦 体现出营养级再野化的理论思想。

“廊道”方面，由于村庄、农田、铁路、公路等阻 隔，东北虎豹栖息地存在严重的割裂和碎片化等问题。 疏通迁移扩散廊道, 实现东北虎豹栖息地贯通是《规 划》的重要内容, 具体举措包括加强隧道上方森林植被

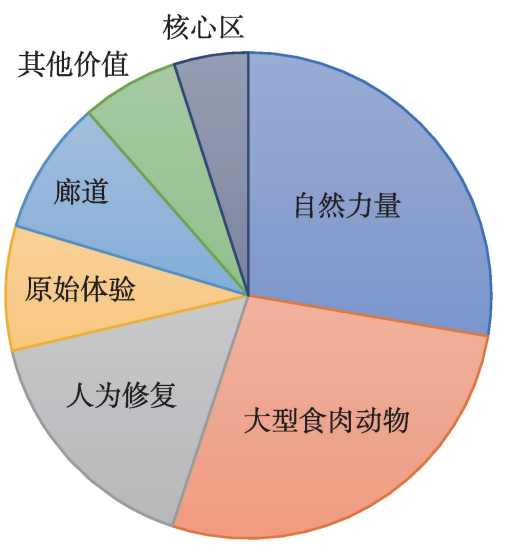

图 4 《规划》关键词比例

Fig. 4 Keyword proportion of Plan 修复、整合撤并生态廊道上的林场、改造廊道关键区域的森林类型以满足东北虎豹及其 猎物的偏好、强化道路管控等，主要涉及穆棱东北红豆杉保护区、嘎呀河湿地公园等。

“核心区”方面，《规划》将虎豹公园划分为 4 个功能区。核心保护区和恢复扩散区 是公园主体，占公园总面积的 $89.06 \%$ ，其中核心保护区又是维护种群正常繁衍、迁移扩 散的关键, 因此在规划期优先采取严格管控措施。特别保护区面积占比较小, 但与上述 
两种功能区同样被列为重点保护区域 （表3）。重点保护区域的划定明确了 一系列限制、禁止行为, 可有效降低 人类活动对野生动物栖息、繁衍等活 动及其生存空间的干扰。

通过以上分析发现，《规划》与 再野化理论联系紧密 (表4), 对东北 虎豹种群和栖息地的保护有利于维持 营养级复杂性; 通过林场撤并、道路 管控等措施疏通生态廊道可以促进东 北虎豹扩散，也意味着部分生产性土 地的废弃; 而分区管理则可以有效降 低人类活动对东北虎豹的影响。此 外，《规划》也充分考虑了弱化人虎 冲突、经济社会发展与动物保护协调 等事项，以促进虎豹公园的可持续发 展。《规划》文本与 “3C” 模型和

“TSD”模型中的各要素并非完全一一对)

\section{表 3 虎豹公园功能区划}

Table 3 Functional zoning of the Northeast Tiger and Leopard Park

\begin{tabular}{lcc}
\hline \multirow{2}{*}{ 区划 } & \multicolumn{2}{c}{ 范围 } \\
\cline { 2 - 3 } & 面积 $/ \mathrm{hm}^{2}$ & 总占比 $/ \%$ \\
\hline 核心保护区 & 627605 & 42.05 \\
特别保护区 & 91810 & 6.15 \\
恢复扩散区 & 701622 & 47.01 \\
镇域安全保障去 (固定) & 40416 & 2.71 \\
镇域安全保障去 (临时) & 31147 & 2.08 \\
总计 & 1492600 & 100 \\
\hline
\end{tabular}

表 4 《规划》文本与再野化理论对应关系

Table 4 The corresponding relationship between the Plan and rewilding theory

\begin{tabular}{lll}
\hline “3C” 模型 & “TSD” 模型 & 《规划》文本 \\
\hline 食肉动物 & 营养级复杂性 & 保护东北虎豹种群 \\
廊道 & 扩散 & 疏通生态廊道 \\
核心区 & 随机扰动 & 分区管理, 降低人类活动干扰 \\
\hline
\end{tabular}

\section{3 人工干预色彩浓厚,生态再野化特征突出}

《规划》明确提出要减少自然生态系统的人为干扰，以体现 “自然力量”，然而同时 强调栖息地修复, 尤其指出要采用先进恢复和治理技术丰富生物多样性, 恢复生态环 境。自动编码结果显示, “人为修复” 内容广泛, 占比达 $16.25 \%$, 仅次于 “自然力量” 和 “大型食肉动物”。《规划》中提及一系列土地修复方式，例如，通过种植谷类、块茎 类作物等人工方式对林场场址进行植被恢复; 采用土壤整治、植被恢复、微生物技术等 对废弃工矿用地进行生态修复; 通过挖方、填方等方式, 营造微地形, 这些都是生态再 野化的典型特征，体现出强烈的人工干预色彩。

《规划》还指出要通过多种方式开展有特色的自然教育, 在大荒沟等旅游景区以及适 宜的自然保护区和森林公园举行森林体验活动，不仅有助于促进公众认识荒野、热爱荒 野，而且能够推进公民生态道德建设，能产生经济社会文化综合价值。“原始体验” 和 “其他价值” 正是荒野区 “具有生态、地质或其他科学特征, 具有教育、景观或历史价 值特征” 的体现。

\section{4 结论与展望}

自然保护地是生态建设核心载体，建立以国家公园为主体的自然保护地体系，是推 进 “五位一体” 总体布局的重大理论和实践创新。作为自然保护地体系的内在组成部分

荒野，也开始引起国内学界关注。荒野保护思想在西方国家有二百多年历史，中国 传统荒野思想则更早。但是，作为科学的荒野保护理论发展仅五十多年，再野化历史则 更短, 从理论构建到工程实验不过二十年。以国家公园为主体的自然保护地体系的确 立, 是强调绿色发展、人与自然和谐共生发展的必然结果, 它有利于实行最严格的生态 
保护、加强山水林田湖草生命共同体的永续保护，从而保障国家生态安全。同时，也有 利于处理好 “经济一社会一生态” 系统中的复杂关系，从而形成人与自然和谐发展的新 模式和 “中国经验”。也必须强调，国内对荒野研究和保护实践仍认识不足，对荒野保护 区关注不够，尤其是在我国现有自然保护地体系中缺乏对荒野保护地的统筹考虑，尚未 建立起与 IUCN管理分类体系相衔接的机制 ${ }^{[32]}$ 。

关注荒野并进行持续的再野化工程实验，是人类文明在城市化、工业化发展到相对 成熟阶段的必然要求, 对荒野资源及生态系统的跨学科研究也正成为研究热点。如曹越 等 ${ }^{[33]}$ 阐述了中国荒野研究框架, 同时提出了十项关键课题。再野化理论的提出, 极大地 促进了荒野科学发展和荒野保护实践。运用 NVivo 对《规划》进行政策文本分析发现， 《规划》较好地体现了荒野保护思想, 与再野化理论的各要素有较高的契合度, 规划了 “核心区” “廊道” 和 “食肉动物种群保护”, 营养级再野化特征较为显著, 但人工干预色 彩浓厚，生态再野化特征突出。未来，可进一步拓展数据来源，结合东北虎豹国家公园 的管理实践，深人研究自然保护地体系中荒野保护、营养级再野化、人工干预强度等一 系列理论、实证问题; 充分借鉴欧美再野化经验，同时植根于中国文化背景、经济社会 发展现状和退耕还荒、退林还荒等实践，探索还荒与再野化的内在关系。此外，应推动 “荒野” 进人土地利用分类，构造政府、社区、企业、研究机构多主体参与的再野化网 络, 循序渐进地推进再野化理论的中国实践，最终实现生态保护与经济社会协调发展。

\section{参考文献(References):}

[1] DUDLEY N (Editor-in-Chief). Guidelines for Applying Protected Area Management Categories. Gland: IUCN, 2008: 1124.

[2] HENDERSON D. American wilderness philosophy. https://www.iep.utm.edu/am-wild/, 2020-02-10.

[3] THOREAU H D. Walking. http://www.gutenberg.org/files/1022/1022-h/1022-h.htm, 2017-07-22.

[4] 严玉芳. “砖瓦进军”与环境诉求: 19 世纪伦敦汉普斯特德荒野保护过程探析. 东北师大学报: 哲学社会科学版, 2016, 66(6): 152-158. [YAN Y F. "The march of bricks and mortar" and environmental demand: An analysis on the preservation process of Hampstead Heath in the 19th century London. Journal of Northeast Normal University: Philosophy and Social Sciences, 2016, 66(6): 152-158.]

[5] MARSHALL R. The problem of the wilderness. The Scientific Monthly, 1930, 30(2): 141-148.

[6] FLADER S. Aldo leopold and the land ethic. In: SAUER T, NORMAN J, SIVAKUMAR M. Sustaining Soil Productivity in Response to Global Climate Change: Science, Policy and Ethics. Oxford: John Wiley \& Sons, 2011: 43-65.

[7] 周自强. 中国经济通史: 先秦经济卷(下): 第2 版. 北京: 中国社会科学出版社, 2007: 791. [ZHOU Z Q. General History of China's Economy: Economic Volume of Pre-Qin Dynasty (Part II): 2nd edition. Beijing: China Social Science Press, 2007: 791.]

[8] 姚晓娜. 荒野观念及其本土化建构. 南京工业大学学报: 社会科学版, 2019, 18(1): 11-17, 111. [YAO X N. The concept of wilderness and its localization construction. Journal of Nanjing University of Technology: Social Science Edition, 2019, 18(1): 11-17, 111.]

[9] 蔡君. 美国荒野的保护管理及使用限制. 北京林业大学学报: 社会科学版, 2005, 4(1): 34-39. [CAI J. Wilderness protection and use limits in America. Journal of Beijing Forestry University: Social Sciences, 2005, 4(1): 34-39.]

[10] Congress of the United States. The wilderness act. http://www.wilderness.net/nwps/legisact, 2020-02-10.

[11] 曹越, 杨锐. 美国国家荒野保护体系的建立与发展. 风景园林, 2017, 144(7): 30-36. [CAO Y, YANG R. The establishment and development of the national wilderness preservation system in the United State. Landscape Architecture, 2017, 144(7): 30-36.]

[12] BORRINI-FEYERABEND G, DUDLEY N, JAEGER T, 等 编著. IUCN 自然保护地治理: 从理解到行动. 朱春全, 李 
叶, 赵云涛, 等 译. 北京: 中国林业出版社, 2015: 12. [BORRINI-FEYERABEND G, DUDLEY N, JAEGER T, et al. (Editor). IUCN Nature Reserve Governance: From Understanding to Action. Translated by ZHU C Q, LI Y, ZHAO Y T, et al. Beijing: China Forestry Press, 2015: 12.]

[13] CASSON S A, MARTIN V G, WATSON A, et al. Wilderness Protected Areas: Management Guidelines for IUCN Category 1b Protected Areas. Gland Switzerland: IUCN, 2016: 8.

[14] 宫丽彦, 程磊否, 卢琦. 荒地的概念、分类及其生态功能解析. 自然资源学报, 2015, 30(12): 1969-1981. [GONG L Y, CHENG L L, LU Q. The concept, classification and ecological function analysis of wasteland. Journal of Natural Resources, 2015, 30(12): 1969-1981.]

[15] 郭建平, 高素华, 刘玲. 我国西部地区农业开发与农业气候资源高效利用. 资源科学, 2002, 24(2): 22-25. [GUO J P, GAO S H, LIU L. Agricultural development and efficient utilization of agricultural resources in western region of China. Resources Science, 2002, 24(2): 22-25.]

[16] 金正波, 吴月. 湖心岛咋就被“全圼”成这样?. 人民日报, 2019-12-09(7). [JIN Z B, WU Y. How did Huxin Island be "fully cultivated" like this?. People's Daily, 2019-12-09(7).]

[17] SOULÉ M E, NOSS R. Rewilding and biodiversity: Complementary goals for continental conservation. Wild Earth, 1998, 8(3): 18-28.

[18] 罗明, 曹越, 杨锐. 荒野保护与再野化: 现状和启示. 中国土地, 2019, (8): 4-8. [LUO M, CAO Y, YANG R. Wilderness protection and rewilding: Current situation and enlightenment. China Land, 2019, (8): 4-8.]

[19] JØRGENSEN D. Rethinking rewilding. Geoforum, 2015, 65(1): 482-488.

[20] 范建红, 刘雅熙, 朱雪梅. 欧洲荒野景观再野化的发展与启示. 中国园林, 2019, 35(12): 106-110. [FAN J H, LIU Y X, ZHU X M. The development and enlightenment of the rewilding of European wilderness landscape. Chinese Landscape Architecture, 2019, 35(12): 106-110.]

[21] SVENNING J C, PEDERSEN P B M, DONLAN C J, et al. Science for a wilder Anthropocene: Synthesis and future directions for trophic rewilding research. PNAS, 2016, 113(4): 898-906.

[22] 艾伦·沃森, 斯蒂夫・卡佛, 黄澄, 等. 荒野、再野化与自主性生态系统: IUCN-1b 类保护地管理中的概念演进. 中国园 林, 2017, 33(6): 34-38. [WATSON A, CARVER S, HUANG C, et al. Wilderness, rewilding and free-willed ecosystems: Evolving concepts in stewardship of IUCN protected category $1 \mathrm{~b}$ areas. Chinese Landscape Architecture, 2017, 33(6): 34-38.]

[23] PERINO A, PEREIRA H M, NAVARRO L M, et al. Rewilding complex ecosystems. Science, 2019, 364(6438): 351359.

[24] NAVARRO L M, PEREIRA H M. Rewilding abandoned landscapes in Europe. In: PEREIRA H M, NAVARRO L M. Rewilding European Landscapes. Cham: Springer, 2015: 3-23.

[25] LORIMER J, SANDOM C, JEPSON P, et al. Rewilding: Science, practice, and politics. Annual Review of Environment and Resources, 2015, 40(1): 39-62.

[26] SANDOM C J, DEMPSEY B, BULLOCK D, et al. Rewilding in the English uplands: Policy and practice. Journal of Applied Ecology, 2019, 56(2): 266-273.

[27] 柯进华. 生态文明视域下的荒野观重塑. 宁夏社会科学, 2019, 38(2): 54-59. [KE J H. Reshaping wilderness view from the perspective of ecological civilization. Social Sciences in Ningxia, 2019, 38(2): 54-59.]

[28] 宋峰, 代莹, 史艳慧, 等. 国家保护地体系建设: 西方标准反思与中国路径探讨. 自然资源学报, 2019, 34(9): 18071819. [SONG F, DAI Y, SHI Y H, et al. Construction of national protected areas system: A reflection on the westernbased criteria and exploration of a Chinese approach. Journal of Natural Resources, 2019, 34(9): 1807-1819.]

[29] 魏钰, 雷光春. 从生物群落到生态系统综合保护: 国家公园生态系统完整性保护的理论演变. 自然资源学报, 2019, 34(9): 1820-1832. [WEI Y, LEI G C. From biocenosis to ecosystem: The theory trend of conserving ecosystem integrity in national parks. Journal of Natural Resources, 2019, 34(9): 1820-1832.]

[30] 杨锐, 曹越. “再野化”: 山水林田湖草生态保护修复的新思路. 生态学报, 2019, 39(23): 8763-8770. [YANG R, CAO Y. Rewilding: New ideas for ecological protection and restoration projects of mountains-rivers-forests-farmlands-lakesgrasslands. Acta Ecologica Sinica, 2019, 39(23): 8763-8770.]

[31] 潘虹, 唐莉. 质性数据分析工具在中国社会科学研究的应用: 以 Nvivo 为例. 数据分析与知识发现, 2020, 4(1): 51- 
62. [PAN H, TANG L. Qualitative data analysis in Chinese social science studies: The case of Nvivo. Data Analysis and Knowledge Discovery, 2020, 4(1): 51-62.]

[32] 曹越, 龙瀛, 杨锐. 中国大陆国土尺度荒野地识别与空间分布研究. 中国园林, 2017, 33(6): 26-33. [CAO Y, LONG Y, YANG R. Research on the identification and spatial distribution of wilderness areas at the national scale in Mainland China. Chinese Landscape Architecture, 2017, 33(6): 26-33.]

[33] 曹越, 杨锐. 中国荒野研究框架与关键课题. 中国园林, 2017, 33(6): 10-15. [CAO Y, YANG R. The research framework and key issues of Chinese wilderness studies. Chinese Landscape Architecture, 2017, 33(6): 10-15.]

\title{
Prospect of the development of Northeast Tiger and Leopard National Park based on the theory of rewilding: Comments on the thought and practice of wilderness protection
}

\author{
WANG Hong-xin ${ }^{1,2}$, SHAO Jun-lin ${ }^{1,3}$, YU Shu-ting ${ }^{3}$, WANG Ying-hui ${ }^{3}$, FENG Yu ${ }^{3}$ \\ (1. Academy for Global Development, Beijing Normal University, Beijing 100875; \\ 2. China Academy of Social Management/School of Sociology, Beijing Normal University, Beijing 100875; \\ 3. School of Government, Beijing Normal University, Beijing 100875)
}

\begin{abstract}
Establishing a protected area system centered on national parks is a theoretical and practical innovation to promote the strategy of "Five in One". Through the analysis of the origin, development process, and practice of the thought of wilderness protection, this paper expounds the internal relationship between wilderness and protected area system. On this basis, this paper reviews "3C" Model, trophic rewilding and "TSD" Model in rewilding theory and analyzes the Master Plan of Northeast Tiger and Leopard National Park (2017-2025) (Draft for Comments) with NVivo. The Plan conforms to rewilding theory and reflects the idea of wilderness protection characterized by trophic rewilding. It also involves strong artificial intervention and shows marked features of ecological rewilding. It is an inevitable requirement to place emphasis on wilderness and rewilding when urbanization and industrialization develops into a mature stage. The national parks should continue the practice of rewilding to provide support for the development of wilderness science and engineering.
\end{abstract}

Keywords: wilderness; rewilding; protected area system; national park 